\title{
El impulso de la publicidad viral cinematográfica: Prometheus (Ridley Scott, 2012) y su ensayo 'transmediático'
}

\author{
Enrique CARrasco Molina \\ Universidad Europea de Canarias \\ enrique.carrasco@uem.es
}

\begin{abstract}
Resumen
Prometheus (Ridley Scott, 2012) ha puesto sobre el escenario de la creatividad publicitaria una hasta ahora inédita propuesta online que, apareciendo de forma viral, gradual y creciente, ha generado una expectación exponencial hasta ahora nunca vista en Internet. El poder de estos recursos promocionales ha favorecido notablemente a que un film con un presupuesto de 130 millones de dólares logre ingresar en taquilla casi cuatro veces más (400 millones de dólares). Y a ello ha contribuido sensiblemente el hecho de que, entre otras muchas cosas, se hayan emitido hasta cuatro versiones distintas del tráiler, con más de 16 millones de descargas del tráiler oficial en YouTube, subido el 22 de diciembre de 2011, seis meses antes de que se estrenara la película en Estados Unidos (6/6/2012). La presente comunicación analiza estructuralmente cómo, a partir del concepto actual de marketing viral, Ridley Scott interpela su futuro espectador colando mensajes encriptados, algunos de apariencia perceptiva subliminal, gracias a bocetos previos del film, secuencias que van a ser descartadas, contenidos extra, vídeos colaterales de extrema originalidad (David 8), así como webs simultáneas (sobre Weyland Industries), todo ello bajo una capa estética extraordinariamente sugestiva que hereda interesantes elementos de Alien, el octavo pasajero (1979), un icono irreprochable de la historia del cine.
\end{abstract}

Palabras clave: Publicidad viral; comunicación; tráiler; marketing cinematográfico.

\section{The movie viral advertising boost: Prometheus (Ridley Scott, 2012) and his 'transmedia' essay}

\begin{abstract}
Prometheus (Ridley Scott, 2012 ) has put on the stage of advertising creativity a previously unpublished information online that virally appears, gradual and growing exponentially and it has generated an expectation unseen before on the Internet. The promotional power of these resources has led significantly to a film with a budget of 130 million dollars and has collected almost four times (400 million dollars) at the box office. And this has contributed significantly to the fact that this movie has released four different versions of the trailer, with over 16 million downloads of the official trailer on YouTube, uploaded on December 22, 2011, six months before that the film was released in the United States (6/6/2012). This communication analyzes structurally how, from the current concept of viral marketing, Ridley Scott challenges and seduces his spectator with encrypted messages, subliminal previous sketches of the film, discarded sequences, extra content, original videos (David 8) as well as simultaneous sites (Weyland Industries), all under an extraordinarily attractive atmosphere inherited from Alien (1979), an unbeatable icon of film history.
\end{abstract}

Key words: Viral advertising; communication; trailer; movie marketing. 


\section{Referencia normalizada:}

Carrasco Molina, E. (2013) El impulso de la publicidad viral cinematográfica: Prometheus (Ridley Scott, 2012) y su ensayo 'transmediático'. Historia y Comunicación Social. Vol. 18. N ${ }^{\circ}$ Especial Diciembre. Págs. 89-103.

Sumario: 1. Introducción. 2. Metodología empleada. 3. Apartados. 3.1. Una campaña viral 'transmediática'. 3.2. Cuantificación de la Campaña Audiovisual.3.3. Cronología de la Campaña Audiovisual. 3.4. Otros medios digitales y redes sociales. 3.5. Contenidos virales de apariencia subliminal. 4. Conclusiones. 5. Referencias bibliográficas. 6. Notas.

\section{Introducción}

La maquinaria promocional de los grandes estudios cinematográficos está valorando con cifras jugosas la velocidad vertiginosa con la que crece la comunicación viral (especialmente en las redes sociales) para comercializar con calculado anticipo un tipo de género fílmico, el de fantasía y ciencia ficción, que es muy proclive a brillar con luz propia en los entornos virtuales visitados por internautas cinéfilos de todo el mundo.

La industria del séptimo arte evoluciona en la red tanto o más que otras manifestaciones culturales porque se trata de un ambiente muy favorable para propiciar el visionado de recursos audiovisuales que integran las campañas de publicidad previa de los estrenos, especialmente los tráileres o teasers que tan bien funcionan como spots anticipatorios.

Simultáneamente al momento del estreno en salas, también antes y después del mismo, los comentarios afines (algunos más versados que otros ) fluyen entre los internautas con especial celeridad. Sobre este terreno, la importancia de las redes sociales ha llegado a ser tal que incluso muchas producciones ya nacen con una marca, un brand apriorístico que puede determinar su funcionamiento, o no, en las salas de exhibición.

Quienes tienen la responsabilidad de poner las bases creativas de las campañas que impulsan el cine como producto comercial, se están beneficiando de una experiencia que han ido adquiriendo con cierta perspectiva en los últimos años y, por eso, de entrada, colocan, junto a las ventanas donde se pre-visualizan los tráileres o teasers, iconos que conectan con Tuenti, Twitter, Facebook o YouTube.

Todas estas herramientas digitales facilitan a los espectadores la posibilidad de elegir cualquiera de estos enlaces para compartir o enviar mensajes, tweets o comentarios, o pinchar en el ya clásico botón de Me gusta, de Facebook, que multiplica la concatenación de juicios referentes a lo que de momento se sabe de un film que se va a estrenar, no ahora, sino en los siguientes seis meses. 
Éste es el insólito caso de Prometheus (Ridley Scott, 2012), que ha puesto sobre el escenario de la creatividad publicitaria un hasta ahora inédito edificio de informaciones online que, apareciendo de forma viral, gradual y creciente, ha generado una expectación exponencial hasta ahora nunca vista en Internet.

El poder de estos recursos promocionales ha favorecido notablemente que un film con un presupuesto de 130 millones de dólares logre ingresar en taquilla casi cuatro veces más (402.486.687 \$, más de 402 millones de dólares hasta diciembre de 2012, según IMDB). (1)

Y a ello ha contribuido sensiblemente el hecho de que, entre otras muchas cosas, se hayan publicado en Internet cuatro versiones distintas del tráiler, con más de 16 millones de descargas del tráiler oficial en YouTube (Prometheus-Official Trailer [TRUE HD], subido el 22 de diciembre de 2011, casi seis meses antes del estreno en $\operatorname{EEUU}(8 / 6 / 2012)$.

Este inteligente recurso de anticipación que de antemano debería ser desarrollado con una estudiada planificación (para no jugar en contra de las esperanzas de miles de fans que pueden percibir que 'se les hace esperar demasiado'), ya ha sido empleado en algunos ejemplos puntuales durante los últimos años, sobre todo en películas de gran empaque visual o sofisticados efectos especiales.

Quizá fuera George Lucas quien se atreviera a adelantar un tráiler de La Guerra de las Galaxias. Capítulo1: La amenaza fantasma (Star Wars. Chapter 1: The phantom menace, 1999) varios meses antes del estreno aprovechando el montaje de un conjunto de escenas que ya estaban listas con antelación a pesar de la complejidad de sus efectos visuales.

La situación era bien diferente entonces pues el desarrollo de Internet y las relaciones online entre usuarios se circunscribían sobre todo a "foros" y "chats", germen de lo que más tarde sería un concepto mucho más versátil y amplio de las redes sociales. No olvidemos que uno de los primeros social media fue MySpace, nacido en 2002, tres años después del estreno de la citada película.

Sin embargo, a día de hoy, el mejor ejemplo que está 'incendiando' el entorno cinéfilo online es la secuela de 300 (Zack Snyder, 2007), que lleva por título 300: Rise of an empire (Noam Murro, 2014). La cinta parece seguir los pasos de expectación virtual puestos en marcha por quienes promovieron la campaña publicitaria de Prometheus.

La primera versión del tráiler oficial, lanzado por la productora Warner Bros., se publicó en YouTube el 12 de junio de 2013, anunciándose el estreno mundial de la película en marzo de 2014 (el día 7 en España según información de la web oficial ), casi exactamente medio año después.

La expectación está servida: casi ocho millones de reproducciones (exactamente 7.443.142) han sido efectuadas en aproximadamente tres meses. Pero aún hay más. 
La película ya tiene más de 10 millones de seguidores en Facebook. Todo en apenas dos meses desde el lanzamiento del primer tráiler de Warner Bros.

Si 300 tenía un aval de 456.068.181 dólares (2) recaudados en salas de todo el mundo (lo que sería mejorar lo invertido - 70 millones - en 6,51 veces), Prometheus tenía expectante, mucho antes de su estreno, a toda una legión de incondicionales de la saga, y sobre todo fans del cine de Ridley Scott. (3)

Explorar de nuevo el universo alienígena tenía para la Twentieth Century Fox unas potentes bazas monetarias desde que comenzó la explotación de la franquicia en 1979 hasta 2011, incluyendo los estrenos cinematográficos, DVDs con contenidos adicionales, Blue-ray, y otros, sumando en total casi 558 millones de dólares (557.182.615 \$) de ganancias netas.

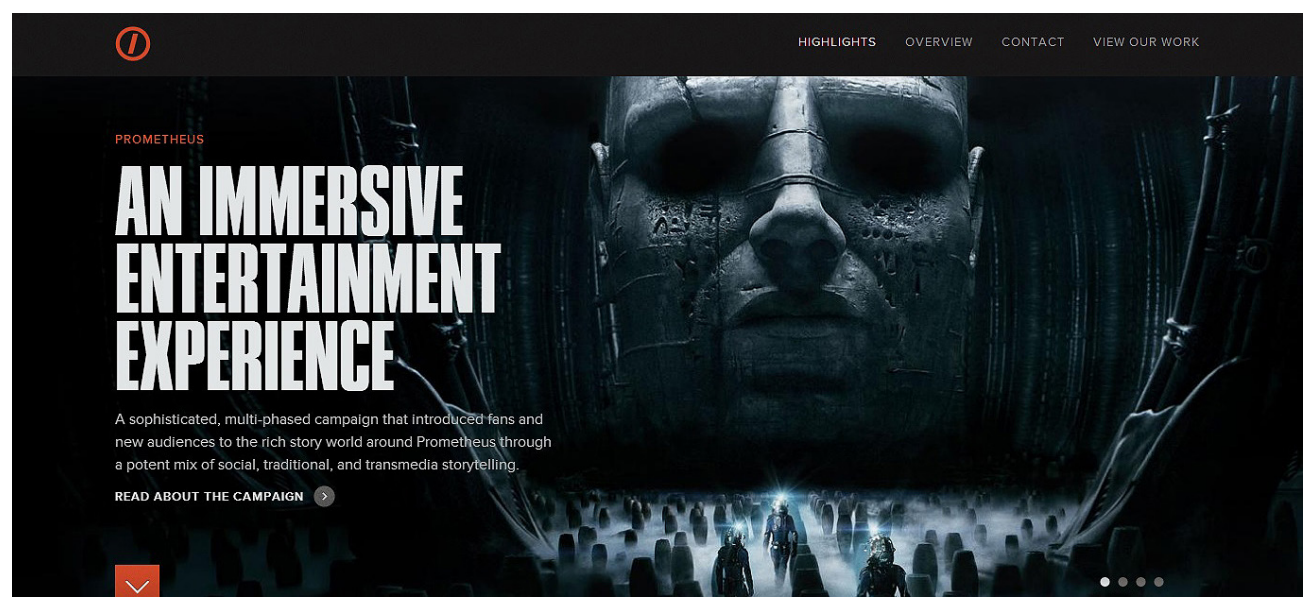

Figura 1. Página de apertura de la web de la agencia Ignition Creative donde el equipo de publicidad contratado para promocionar Prometheus explica cómo se montó la campaña viral el año pasado.

\section{Metodología empleada}

Para la elaboración de este estudio se ha realizado una prospectiva analítica, cuantitativa y cualitativa, de los mensajes publicados en Internet (páginas de información cinematográfica y redes sociales relacionados con la campaña publicitaria previa al estreno del filme.

Este estudio se circunscribe a la naturaleza extremadamente original de la estrategia publicitaria que se pone en marcha para esta película, independientemente de los resultados críticos, que no han sido muy brillantes, pues el guión del film se desmarca de la brillantez de la cinta original de 1979, Alien, el octavo pasajero, argumento en el 
que por vez primera se presentó la historia de la extraña hibridación entre la cultura humana y la alienígena al espectador.

\section{Apartados}

\subsection{Una campaña viral 'transmediática'}

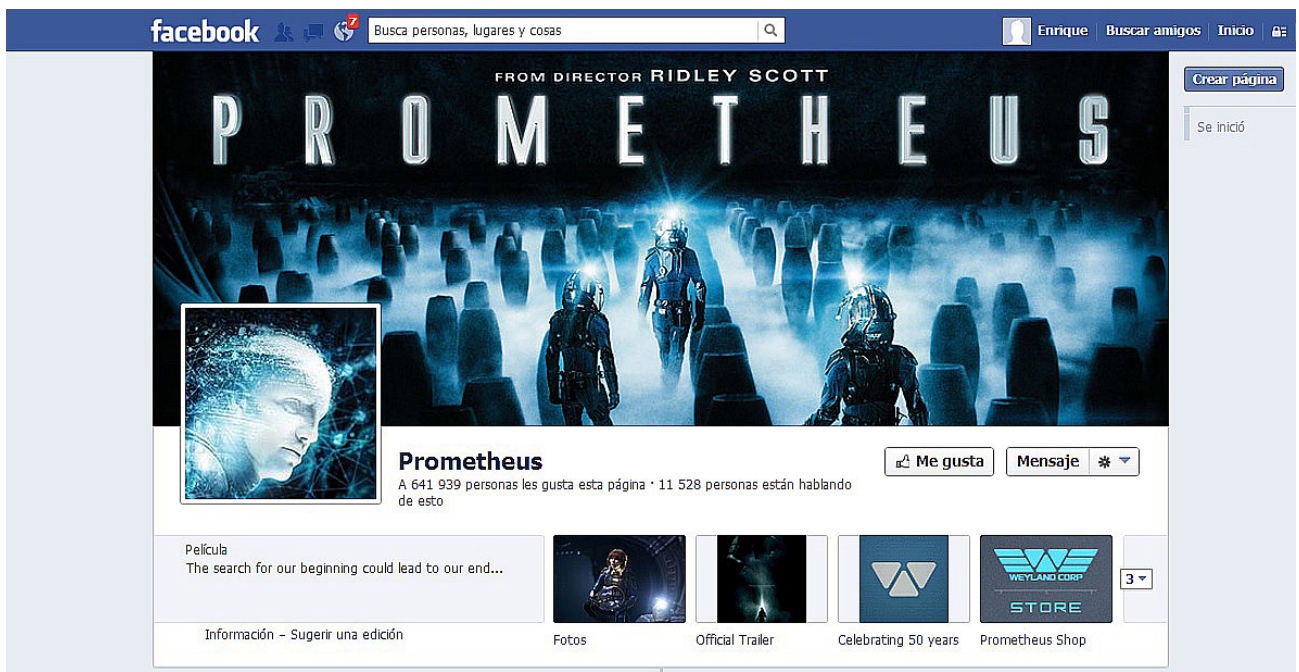

Figura 2. Pantallazo original de la página oficial del film en Facebook, en español, previa al estreno mundial, antes de junio de 2012. Imagen: 20th Century Fox / Scott Free Productions / Dune Entertainment.

La campaña publicitaria previa de Prometheus, difundida preferentemente en medios digitales con mucha mayor presencia que en los medios tradicionales arrancó medio año antes del estreno previsto del film con un concepto 'transmediático' como definían sus promotores y se comentaba en reportajes al respecto.

El equipo creativo de Ignition Creative, agencia de publicidad digital que llevó a cabo la campaña viral de Prometheus con la supervisión cercana de Scott, explicaba en su propia web que "creamos una sofisticada campaña de múltiples fases que introdujo tanto a los fans como a los nuevos públicos que se iban incorporando en el rico y complejo mundo creado alrededor del film a través de una potente mezcla de medios sociales, tradicionales y transmedia. Los vídeos virales TED Talk 2023, David 8 y Quiet Eye fueron creados por Ridley Scott, Damon Lindelof y RSA Films. Toda la campaña se ha presentado en revistas como Forbes, Mashable y Fast Compan como un punto de referencia para el marketing digital." (4) 


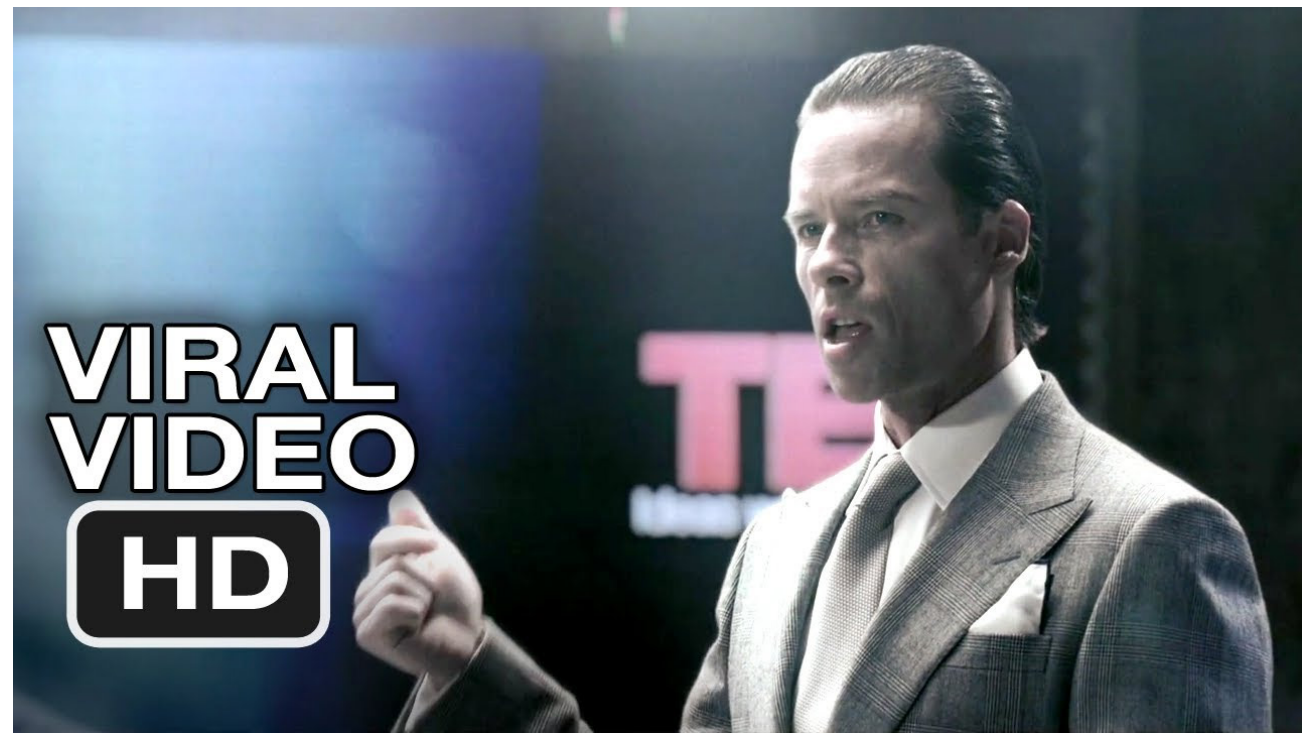

Figura 3. Peter Weyland, líder de Weyland Industries, explica el mito de Prometeo en una delirante secuencia que abre expectativas argumentales en la red pero que no se incluye finalmente en el film. Imágenes: 20th Century Fox / Scott Free Productions / Dune Entertainment.

Jeff Gómez, Simon Pulman, por su parte, comentaron ya en el mes de marzo de 2012 que la publicidad era parte indisoluble de la propia película, en un artículo publicado tres meses antes del estreno. Y también señalaban que se habían visto algunos ejemplos de campañas transmediáticas' virales (combinatoria de medios tradicionales con medios online) de éxito en ciertos espacios televisivos norteamericanos, como el programa gastronómico Bravo. Según postulan Gómez y Pulman la técnica es ir colocando "contenido que está por venir en las redes sociales y en ciertas plataformas online que generan proliferación de comentarios. (5)

Ambos autores están convencidos de que, producida con cuidado y esmero, el concepto de campaña 'transmediática puede "combatir la fatiga del uso excesivo de una marca, lo que es siempre un riesgo en la era digital cuando una persona puede ver un tráiler en YouTube docenas de veces. El nuevo concepto puede darle a los fans un contenido extra, en su justa medida, que puede ser explorado, compartido y discutido sin que todo ello perjudique el engranaje de salida comercial del film." (GÓMEZ, J., y PULMAN, S., 2012).

Ridley Scott ya intuía todo esto y quiso adelantarse a una posible fuga de contenidos que pudieran ensombrecer las dosis de expectativas que se pretendían lanzar en Internet a cuentagotas pero siempre son seguridad. Deseaba que la campaña fuera lo más efectiva posible pero con un control exhaustivo de 'qué' era lo que se tenía que lanzar, 'cómo' se tenía que publicar y 'cuándo'. 
En la búsqueda de un control en el alcance de la campaña viral y para garantizar su éxito, Scott manifestaba en las entrevistas televisivas concedidas durante las campañas previa y simultánea al estreno de Prometheus que les había hecho firmar a todos los miembros del equipo un contrato de confidencialidad para evitar escapes, sobre todo de contenidos del guión, algo que sería perjudicial para mantener la ilusión de los millones de correligionarios de la saga en todo el mundo.

A pesar de todo el empeño puesto, después del estreno, Prometheus ha sufrido irrupciones ciertamente indeseadas por los productores, una serie de recursos videográficos o gráficos muy visitados que, en realidad, han seguido beneficiando el éxito viral de la película. Todos ellos no forman parte de lo que nosotros hemos denominado Campaña Viral Matriz que se compone básicamente del material controlado, diseñado, editado y publicado en orden cronológico bajo la supervisión estrecha de Ridley Scott y de sus colaboradores en la promoción de la cinta.

Javier Cano comenta el éxito de la apuesta viral previa del equipo de Scott con los vídeos TED y David 8, y la presencia online de la web de Weyland Industries que en la ficción celebra su 50 aniversario, y cita algunos datos de éxito de pre-venta publicados en la revista Hollywood Reporter: “(...) dicha campaña ya está arrojando resultados, porque según Hollywood Reporter, la película que se estrena este próximo 31 de mayo en parte de Europa, y el 8 de junio en USA (en España habrá que esperar hasta el lejano 3 de agosto), ya ha vendido más de 18.000 entradas de pre-venta, pulverizando el record de venta anticipada en el Reino Unido." (7)

\subsection{Cuantificación de la campaña audiovisual}

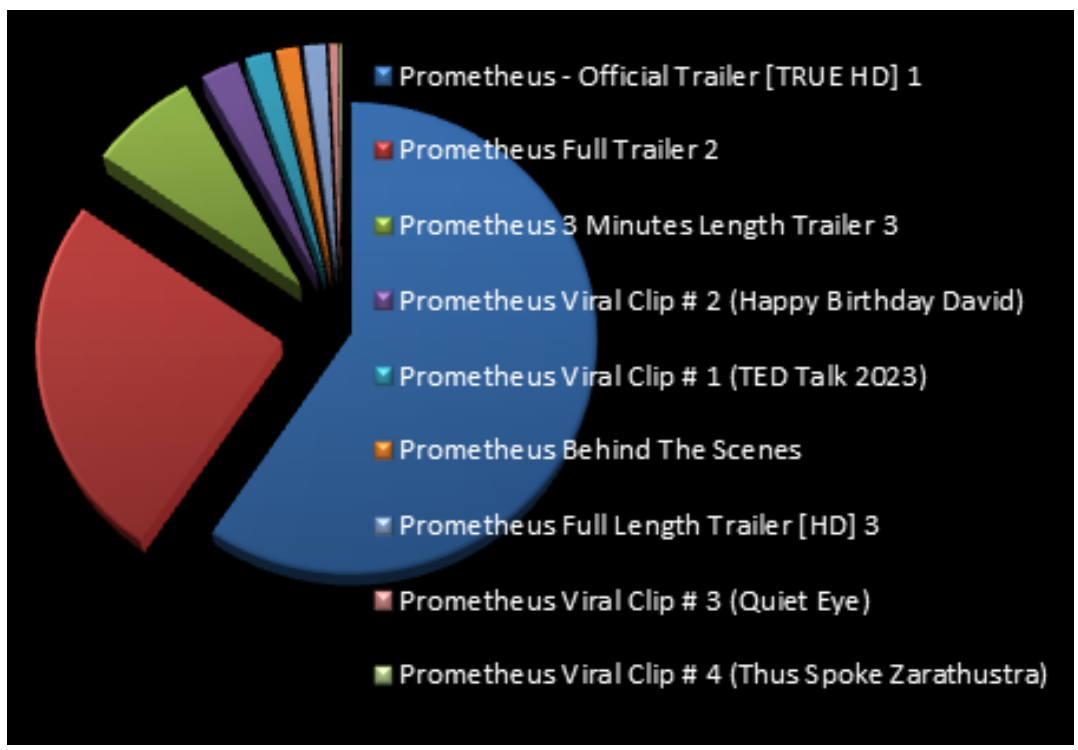

Figura 4. Fuente: Elaboración propia. 
Esta tabla muestra la campaña publicitaria audiovisual por número de reproducciones en YouTube, mostradas de mayor a menor, y de arriba abajo, controladas y difundidas bajo la supervisión directa del equipo de Scott. Los datos están tomados de una muestra consultada en YouTube el 24 de julio de 2013, cuando se comenzó el trabajo de campo de esta ponencia (que se marca temporalmente a un año vista del estreno internacional de Prometheus. Las cifras más importantes de la campaña y su intensidad en la incorporación de nuevos contenidos se mueven cronológicamente entre diciembre de 2011 y julio de 2012, período en el que se producen un mayor número de consultas de alguno de los nueve audiovisuales.

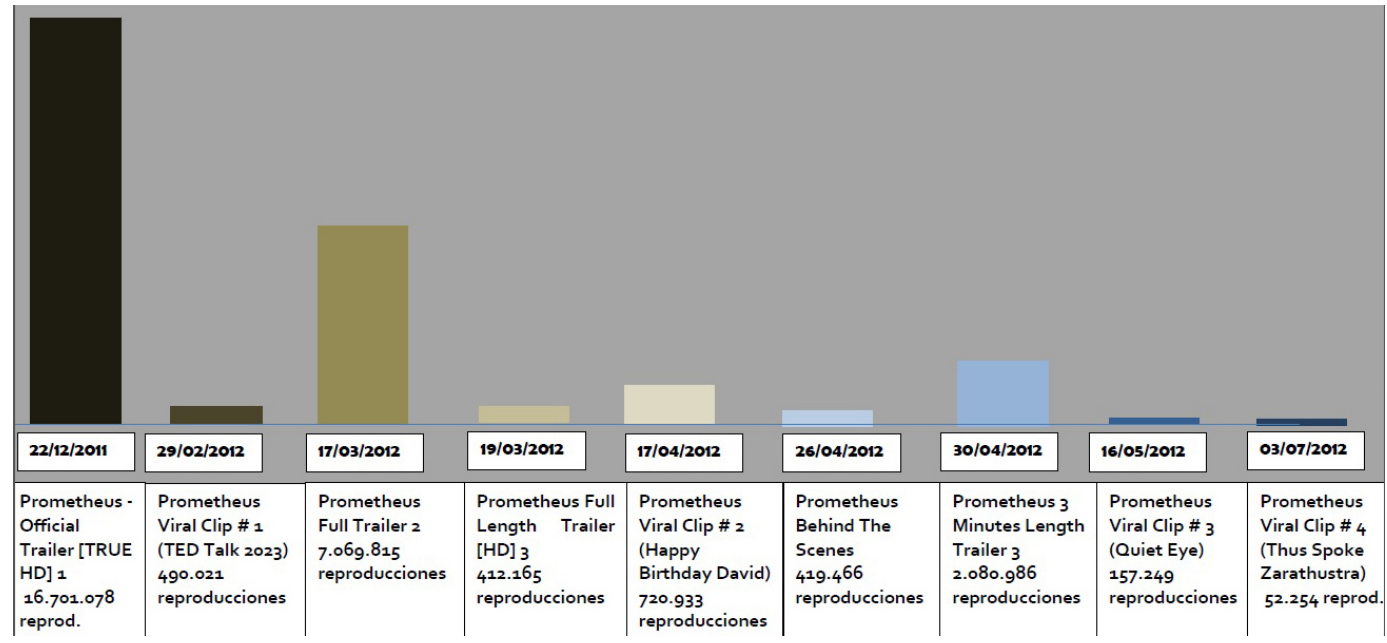

Figura 5: Fuente: Elaboración propia.

\subsection{Cronología de la campaña audiovisual}

Tabla cronológica en la que se aprecia cómo el monto de internautas y posibles espectadores no van aumentando exponencialmente a medida que se visualizan nuevos contenidos virales en el avance cronológico de la campaña. La experiencia evidencia la tendencia de mayor fidelidad a los cuatro tráileres. Los nueve lanzamientos audiovisuales conforman lo que nosotros hemos denominado "Campaña Viral Matriz" (promovida en YouTube) y se desarrolla desde diciembre de 2011, medio año antes del estreno, hasta julio de 2012, un mes después del estreno internacional. También se emitieron otros contenidos no menos interesantes en plataformas online, como la página que desde la ficción conmemora el 50 Aniversario de Weyland Industries (www.weylandindutries.com). El esquema arroja sin embargo datos curiosos y contradictorios. Aunque los vídeos virales lograron sin duda gran expectación y comentarios entre los internautas, se demostró que el formato que sigue funcionando mejor es el tráiler editado con fundidos a negro entre planos rápidos. Efectivamente, los cuatro tráileres divulgados cronológicamente en la red: Prometheus - Official Trailer TRUE HD (22/12/2011), Prometheus Full Trailer 2 (17/03/2012), Prometheus 
3 Minutes Length Trailer 3 (30/04/2013), y Prometheus Full Length Trailer [HD] 3 (19/03/2012), son los recursos que más llegaron al futuro espectador, respectivamente, con $16.701 .078,7.069 .815$, y 412.165 reproducciones. Las piezas autodenominadas "virales" tuvieron desiguales respuestas, pero es destacable la titulada Prometheus Viral Clip 3 \# 2 (Happy Birthday David), con más de 720.000 reproducciones (no en vano la presentación del androide David 8 es una de las contribuciones más originales de la campaña).

\subsection{Otros medios digitales y redes sociales}

A continuación se exponen las cuantificaciones disponibles respecto al impacto del film en algunas plataformas digitales y redes sociales. Según se extrae del medidor Alexa, las mejores palabras clave que han funcionado para hacer una búsqueda de la película, en Internet, han sido: 'prometheus', 'project prometheus', 'weyland prometheus', 'prometheus project' y 'prometheus website', con un porcentaje del tráfico del $41,32 \%, 18,44 \%, 4.40 \%, 3,75 \%$ y un $3,37 \%$, respectivamente.

Sin embargo, tecleando la palabra 'prometheus' en sí misma, sobre todo para buscar información referida al film en mucho mayor medida que alrededor del mito de Prometeo, tuvo una alta concentración en páginas como Internet Movie Data Base (IMDB), Prometheus2-movie, y Wikipedia, con unos porcentajes respectivos de un $30,01 \%, 23,27 \%$, y 20,97\%, relegándose las consultas de You Tube a tan sólo un residual $3,17 \%$.

Gracias a estos datos de los últimos tres meses proporcionados de Alexa concluimos varias cosas:

-Ya ha pasado más de un año desde el estreno de Prometheus y ahora, quienes se definen seguidores de la ansiada secuela Prometheus 2, buscan más información organizada sobre el nuevo proyecto.

-Los visionados en YouTube aún son escasos porque no se ha colgado ningún vídeo viral, ni tráiler.

El material no audiovisual más importante que suministra la campaña publicitaria viral del film se concentra sobre todo en cuatro sitios web: la página oficial del film de Facebook, la cuenta oficial de Twitter (dejó de activarse desde septiembre-octubre de 2012) y dos páginas creadas por el equipo de marketing contratado por Scott y la Fox para posicionar en lo más alto las curiosidades de la audiencia: www.projectprometheus.com y www.weyandindustries.com, ambos sitios con un impresionante background de información proveniente de fuentes de la producción y de fuentes independientes como las aportaciones creativas de los fans.

www.facebook.com - (https://www.facebook.com/PrometheusMovies?fref=ts)

La página oficial de Facebook tiene actualmente 649.761 de seguidores y en su estructura trata de favorecer la concatenación exponencial de comentarios de varios tipos de usuarios: quienes vieron la película y no les gustó, quienes vieron la película 
y les gustó, y quienes no la vieron pero son fans de la saga de películas sobre el mismo monstruo y alimentan un importante contingente de posts en distintos foros y contextos digitales. Otra curiosidad que ha generado cientos de entradas en Facebook: la página que los promotores de la película han otorgado a la intensa creatividad de los diseñadores gráficos que participan con libertad en hacer sus dibujos e interpretaciones plásticas de escenas u objetos de la película. También hay sitio para todos ellos en el enlace 'Prometheus Fan Art'. Estos espacios colaterales han contemplado todo lo que puede caber en la imaginación y mucho más, desde escenas inventadas hasta reconstrucciones escultóricas y pictóricas, esbozos de maquetas de naves espaciales, propuestas de cartelería y mucho más.

@PrometheusMovie

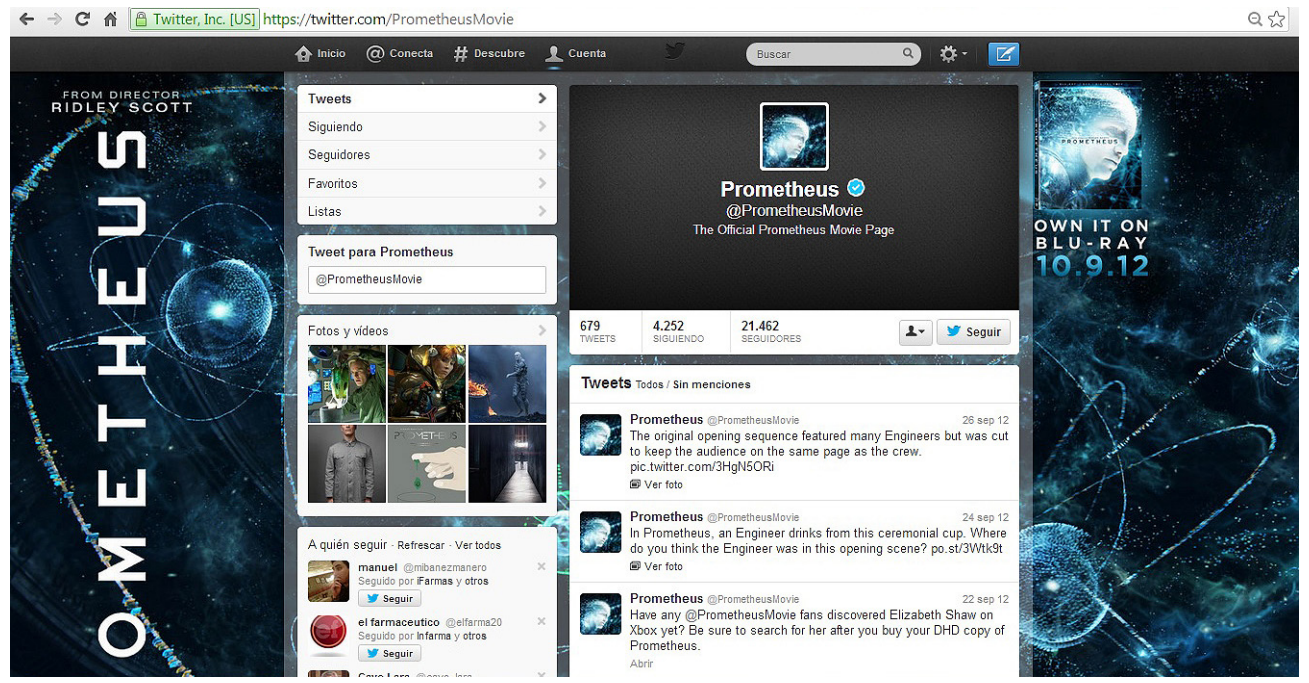

Figura 6. Frontpage del sitio web en Twitter. 20th Century Fox / Scott Free Productions / Dune Entertainment.

Por otra parte, la cuenta del film en Twitter es quizá lo menos reseñable de la esfera online social aunque tiene una cierta lógica dado el carácter extremadamente visual de la película y la posibilidad escasa de sacarle partido a las fotografías y vídeos. Sin embargo, el sitio también incluye algunas fotos y piezas audiovisuales seleccionadas, incluyendo algún trabajo curioso de los fans (muchos de ellos entusiastas de la ciencia ficción y expertos en diseño gráfico).

En total, hasta el momento del último contenido subido (una foto de Michael Fassbender sacando una forma extraña de un frasco, publicada el 31 de octubre de 2012), el sitio ha registrado 679 tweets, 4.252 personas siguiendo y 21.462 seguidores.

www.projectprometheus.com y www.weylandindustries.com 
El Departamento de Propiedad Intelectual de Twentieth Century Fox Film Corporation registró estos dos dominios, respectivamente, el 18 de enero de 2003 y el 26 de enero de 2011, lo que corrobora que el proyecto de Scott ya le rondaba la cabeza por esas fechas mientras preparaba su decimocuarto film, Los impostores.

El ranking global suministrado por Alexa nos dice que el sitio web de projectprometheus tuvo 910.046 impactos en los últimos tres meses, y tiene una peculiaridad: el país que más consultas ha registrado ha sido Irán, con 163.763 impactos. Por su parte, weylandindustries tuvo un total de 722.122 impactos.

Todo el proyecto de Industrias Weyland es una impresionante obra de diseño gráfico realizada con todo lujo de detalles, e incluye cómo surgió en la ficción el macrouniverso Weyland, una gigantesca corporación capaz de crear androides muy perfeccionados (David 8), realizar las prospecciones de mineral más audaces del cosmos y generar recursos tecnológicos de aplicación industrial, médica, energética y de logística para el transporte espacial, entre otras cosas.

Ambas sites, que comparten un diseño similar y una línea proyectiva parecida (la identidad o filosofía de una compañía ultra-tecnológica que busca los orígenes del ser humano en los vestigios planetarios de una antigua cultura alienígena) comparten una presentación que combina una paleta cromática gris, azul y negra se nos exhibe con una apariencia tan brillante que parece totalmente real. Incluso los contenidos son plausibles y muy profesionales en apariencia pese a que nos encontramos ante un supuesto background de ciencia ficción creado expresamente para la película. La web de Weyland Industries fue ganadora de un galardón en los premios Key Art Awards.

\subsection{Contenidos virales de apariencia subliminal}

Finalmente hemos querido comentar la atmósfera que quizá pudiera ser más singular y destacable de la película, además de su atractiva vuelta a los orígenes de Alien, el octavo pasajero en cuanto a las reminiscencias que del arte de Giger se retoman en el diseño de producción y en los decorados de la nave extraterrestre.Scott ha empleado un recurso francamente atractivo para generar, si cabe, mayor crecimiento en el número de comentarios online y, de paso reforzar la virulencia de la campaña en los medios: generar inquietud y misterio desvelando pequeñas piezas que, además, tienen apariencia subliminal.

La idea la encontramos en varios ejemplos gráficos:

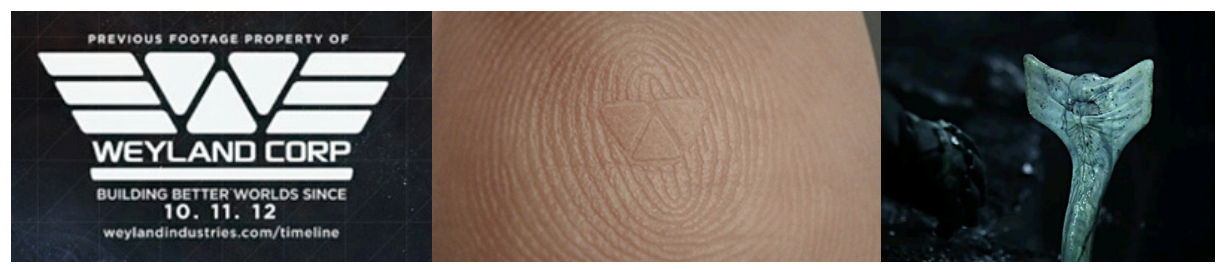

Figuras 7, 8, y 9 (de izquierda a derecha). 20th Century Fox / Scott Free Productions / Dune Entertainment. 
El logo de Weyland Industries figura en todo soporte imaginable, incluyendo algunos menos visibles conscientemente que otros. Lo vemos en la huella digital de David 8 (marca de fábrica indeleble del androide), e incluso en la forma de la cabeza de la monstruosa serpiente que ataca a uno de los exploradores en el planeta alienígena.
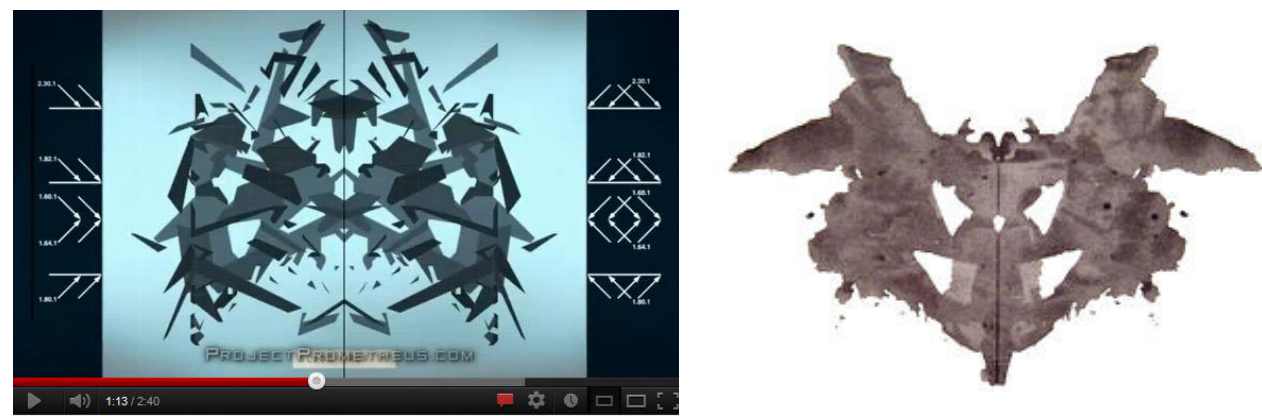

Figuras 10 y 11 (de izquierda a derecha). Izquierda: 20th Century Fox / Scott Free Productions / Dune Entertainment. Derecha: Primera lamina del test. Autor. Hermann Rorschach, 1921.

Por otro lado, el vídeo viral de David 8 pretende colarnos en fracciones de segundos la idea de los diferentes estados de ánimo del inclasificable androide. Para ello se utiliza una especie de máscara compuesta por varios fragmentos que conforman claramente una alusión al Test de Rorschach (1921), técnica de exitosa aplicación posterior en psicoanálisis.

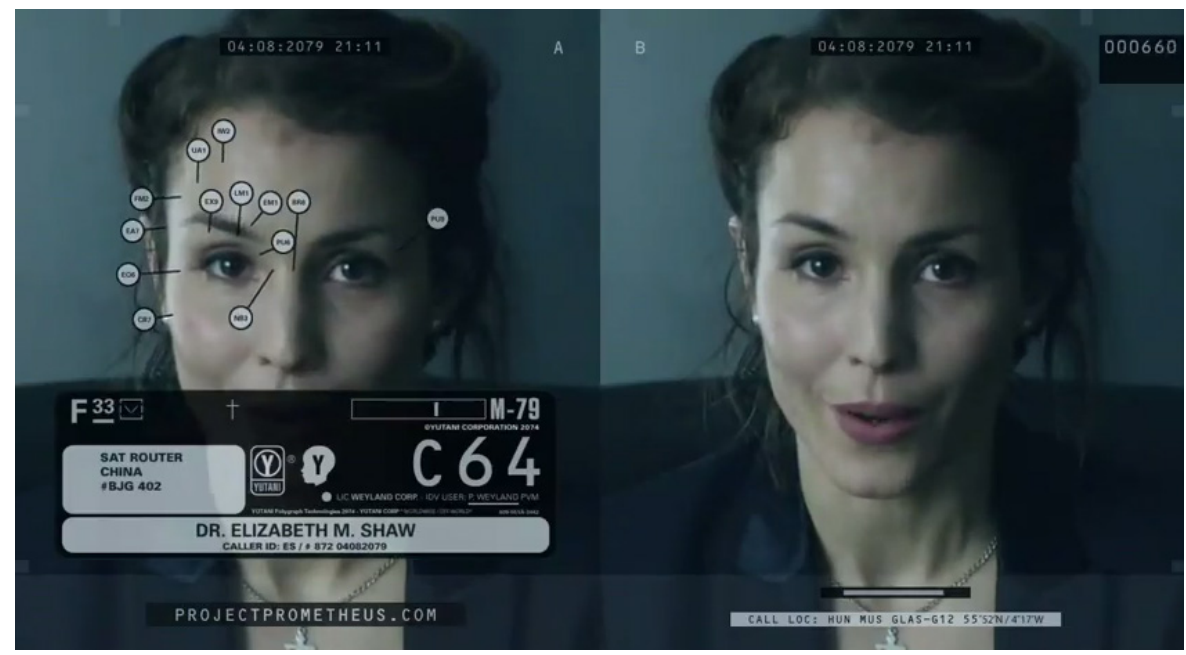

Figura 12: 20th Century Fox / Scott Free Productions / Dune Entertainment.

Finalmente, la pieza Prometheus Viral Clip \# 3 (Quiet Eye) nos desvela un curioso juego visual que introduce en segmentos de tiempo casi imperceptibles para el ojo 
humano rostros de distintas personas, incluyendo el de la doctora Elizabeth Shaw (Noomi Rapace).

\section{Conclusiones}

Al hilo del enorme poder comunicativo que tiene Internet en todos los estratos de nuestra sociedad ( $\sin$ limitaciones de edad, sexo o condición adquisitiva), y en estrecha relación al visionado de cine en línea, no podemos dejar pasar por alto el contundente peso de las redes sociales (Facebook, Twitter, Tuenti, YouTube, etc.) y las propias páginas web especializadas en cine (que pueden ir de la actualidad al coleccionismo, pasando por páginas informativas con ofertas de castings, etc.) dentro del diseño promocional de una cinta.

La libertad de la red condiciona al máximo el monto de comentarios de cinéfilos y espectadores al uso, incluso aunque prefieran la música u otro canal de entretenimiento antes que el cine: su coparticipación masiva online en el juicio de una película puede ser decisiva desde el punto de vista del rendimiento del film.

Esta conclusión es la que centraliza el sentido del. Prometheus y su original campaña viral y transmediática está sirviendo de ejemplo a imitar por otras producciones que buscan generar la máxima expectativa con la máxima anticipación temporal antes del estreno en salas, sobre todo en casos de películas de gran empaque y considerables medios técnicos.

El punto de inflexión que probablemente diferencie Prometheus de otras películas que decidan plantear una campaña viral de similares características estriba en las decisiones finales arriesgadas puestas en marcha por Scott, un director que, aunque bien asesorado, tiene una intuición comercial mucho más avanzada que otros colegas cineastas de su misma generación. En este sentido nos referimos especialmente a planificar proyectos online muy ambiciosos como la web de Weyland Industries, o el hecho de rodar y editar piezas audiovisuales (David 8, TED Talk 2023, Quite Eye, etc.) muy interesantes y de gran impacto visual que finalmente no se incluyen en el montaje final de la película.

Pocos directores aprobarían dejar fuera algunos de estos materiales, pero Scott sí lo hizo en beneficio de crear una más brillante y expectante campaña promocional previa a la presentación oficial de la cinta. 


\section{Referencias bibliográficas}

Libros:

CARRASCO MOLINA, Enrique (2011): La crítica de cine, metodología para investigadores: la reseña audiovisual en los nuevos escenarios de la comunicación , Tauro Ediciones. Madrid.

Artículos en publicaciones web:

AAVV. Entrada de Prometheus en la Enciclopedia Wikipedia.

AAVV. Comentarios del equipo de Ignition Creative en su web, 8 de junio de 2012. Disponible en http://ignitioncreative.net/interior.html\#/blog/816. Consultado el 22 de septiembre de 2013.

CANO, J. (10 de mayo de 2012). "Prometheus" Información, tráiler y una magistral campaña viral, en el blog FREAKSOCIETY. Un refugio para los culturalmente amalgamados.Disponible en http://freaksociety.wordpress.com/2012/05/10/ prometheus-informacion-trailer-y-una-magistral-campana-viral/. Consultado el 30/07/ 2013.

CARRASCO MOLINA, E. (2012). Apuntes sobre la percepción inconsciente en el cine. El ejemplo de Alien, el octavo pasajero (1979) y su propuesta orgánica de atracción/repulsión, en Revista Mediterránea de Comunicación. Universidad de Alicante. Año 3, Vol. 3, No 2 (2012), publicado el 21/07/2012. Disponible en http://mediterranea-comunicacion.org/index.php?journal=Mediterranea\&page $=$ article \&op $=$ view $\&$ path $\% 5 B \% 5 \mathrm{D}=34$. Consultado el 15 de septiembre de 2013.

CORLISS, R. (14 de marzo de 2007). Times (ed.): 7 Reasons Why 300 Is a Huge Hit. Consultado por el autor de la ficha que muestra Wikipedia sobre el film el 5 de septiembre de 2009. Disponible en http://es.wikipedia.org/wiki/300_(película). Consultado el 21 de septiembre de 2013.

GÓMEZ, J., PULMAN, S. (March 23, 2012): In Ridley Scott's 'Prometheus,' the Advertising Is Part of the Picture, en Ad Age Digital. Disponible en http:// adage.com/article/digitalnext/ridley-scott-s-prometheus-advertising-part-picture/233452/. [Consultado el 22 de septiembre de 2013].

\section{Notas}

1. $\$ 402,486,687$ (Worldwide. 21 December 2012). Tabla de ingresos detallada por fechas y países de estreno en la ficha del film que se publica en Internet Movie Data Base (IMDB). Disponible en http:// www.imdb.com/title/tt1446714/business. [Consultado el 30 de julio de 2013].

2. Box Office Mojo (IMDB). Disponible en http://www.boxofficemojo.com/movies/?id=300.htm. [Consultado el 21 de septiembre de 2013]. 
3. CORLISS, R (14 de marzo de 2007). Times (ed.): 7 Reasons Why 300 Is a Huge Hit. Consultado por el autor de la ficha que muestra Wikipedia sobre el film el 5 de septiembre de 2009. Disponible en http://es.wikipedia.org/wiki/300_(película). [Consultado el 21 de septiembre de 2013].

4. Comentarios del equipo de Ignition Creative en su web, 8 de junio de 2012. Disponible en http:// ignitioncreative.net/interior.html\#/blog/816. [Consultado el 22 de septiembre de 2013].

5. GÓMEZ, J., PULMAN, S. (March 23, 2012). In Ridley Scott's 'Prometheus,' the Advertising Is Part of the Picture, en Ad Age Digital. Disponible en http://adage.com/article/digitalnext/ridley-scott-s-prometheus-advertising-part-picture/233452/. [Consultado el 22 de septiembre de 2013].

6. CANO, Javier (10 de mayo de 2012): "Prometheus" Información, tráiler y una magistral campaña viral, en el blog FREAKSOCIETY.

7. Un refugio para los culturalmente amalgamados. Disponible en http://freaksociety.wordpress. com/2012/05/10/prometheus-informacion-trailer-y-una-magistral-campana-viral/. [Consultado el $30 / 07 / 2013]$.

\section{El autor}

Enrique Carrasco Molina es licenciado en Ciencias de la Información por la Universidad Complutense de Madrid (1990) (Comunicación Audiovisual), y doctor en Ciencias de la Información por la Universidad de La Laguna (1996), (Comunicación Audiovisual). Ha trabajado durante años como periodista y crítico de cine en $E l$ Día, Diario de Avisos, El Mundo-La Gaceta de Canarias, y como jefe de prensa para varias entidades públicas y privadas. En 2004 creó su propia empresa, desde la que coordinó los contenidos de varias revistas corporativas encargadas por organizaciones privadas y públicas. Ha sido asesor de comunicación de SINPROMI (2009-2010) y docente en centros universitarios privados de Tenerife (ESNE, IEES, MBA Business School, ESM) y, actualmente, en la Universidad Europea de Canarias (Grado de Comunicación Publicitaria), impartiendo las asignaturas de Comunicación Corporativa, Estructura del Sector Publicitario y Taller de Creatividad. Ha desarrollado guiones para series de televisión canarias y también ha dirigido cinco cortometrajes, dos de ellos como codirector. Entre 1988 y 2011 fue crítico de cine en rotativos como Diario de Avisos, El Día, y El Mundo-La Gaceta de Canarias. Es miembro de la Red Internacional de Investigadores e Investigaciones en Comunicación (I\&I), y mantiene en estos momentos algunas líneas de investigación en curso, como' La persuasión del mensaje publicitario en el entorno online'; 'La percepción subliminal publicitaria', 'Cine y Publicidad: Hibridaciones y sinergias' y. 'La eficacia de la publicidad viral para el marketing cinematográfico'. Actualmente es también responsable del Departamento de Comunicación del Colegio Oficial de Farmacéuticos de Santa Cruz de Tenerife. 